- Supporting Information -

\title{
Seeded rods with Ag and Pd bimetallic tips - spontaneous rearrangements of the nanoalloys on the atomic scale
}

\author{
Eran Aronovitch ${ }^{1}$, Lothar Houben², Maya Bar-Sadan ${ }^{1 *}$ \\ 1 Department of Chemistry, Ben-Gurion University of the Negev, Beer-Sheva, Israel \\ 2 Department of Chemical Research Support, Weizmann Institute of Science, Rehovot, Israel
}

\section{Synthesis}

\subsection{Synthesis of CdSe seeds}

The procedure for the CdSe seeds synthesis was adapted from ref 1 . To grow seeds, cadmium oxide (CdO, 0.06g), octadecylphosphonic acid (ODPA, 0.313g) and trioctylphosphine oxide (TOPO, 3g) were mixed together in a $25 \mathrm{ml}$ three-necked flask and brought to $150^{\circ} \mathrm{C}$ under nitrogen. After all the materials dissolved and the mixture became homogenous, the solution was placed under vacuum for 1 hour. Selenium (Se, $0.058 \mathrm{~g}$ in a vial) was dissolved in $1 \mathrm{ml}$ of trioctylphosphine (TOP) under nitrogen at $50^{\circ} \mathrm{C}$. Once the selenium dissolved completely, heating was turned off. The three-neck flask was returned to nitrogen atmosphere, and the temperature was raised to $320^{\circ} \mathrm{C}$. This temperature was maintained for $10-20$ min until the solution turned clear and colorless. The temperature in the flask was raised to $370^{\circ} \mathrm{C}$ and $1.8 \mathrm{ml}$ of TOP was added, followed by a drop of temperature. The temperature was allowed to recover to $370^{\circ} \mathrm{C}$. The TOP:Se solution was then injected quickly to the flask followed by a decrease in temperature to app. $320^{\circ} \mathrm{C}$. The heating mantle was removed 20sec after the injection time. The solution was then allowed to cool down. When the solution temperature reached $100^{\circ} \mathrm{C}, 5 \mathrm{ml}$ of toluene were added to give red-orange color. The products were cleaned by two consecutive steps of precipitation with methanol and redispersion in toluene.

\subsection{Synthesis of seeded nanorods of CdSe@CdS}

CdSe@CdS seeded nanorods were synthesized according to the procedure in ref 2. CdO (0.06g), ODPA (0.29g), hexylphosphonic acid (HPA) (0.08g) and TOPO (3g), were mixed together in a $50 \mathrm{ml}$ three-necked flask at $150^{\circ} \mathrm{C}$ under nitrogen. After all the materials dissolved and the mixture became homogenous, it was placed under vacuum for 1.5 hours. In a separate vial, sulfur (S, 0.08g) was dissolved in $1.8 \mathrm{ml}$ of TOP under nitrogen. Once the Sulfur dissolved completely, $0.4 \mathrm{ml}$ of the previously prepared CdSe seeds solution in toluene $\left(1.45 \cdot 10^{-4} \mathrm{M}\right.$ as determined by absorbance) were injected into the vial and the solution was placed under vacuum at $\sim 50^{\circ} \mathrm{C}$ until all the toluene was evaporated ( 10 min). The temperature in the flask was raised to $320^{\circ} \mathrm{C}$ under nitrogen and kept at that temperature for $10 \mathrm{~min}$ until the solution turned clear and colorless. Then the solution was cooled to $150^{\circ} \mathrm{C}$ and placed under vacuum for an hour before the temperature was raised under nitrogen, to $360^{\circ} \mathrm{C}$. At this stage $1.8 \mathrm{ml}$ of TOP was added and the temperature was allowed to recover. The TOP:S-CdSe solution was then injected quickly to the flask followed by a decrease in temperature to around $310^{\circ} \mathrm{C}$. The temperature recovered within $3.5 \mathrm{~min}$ and remained at $360^{\circ} \mathrm{C}$ for an additional $4.5 \mathrm{~min}$ (total growth time of $8 \mathrm{~min}$ ) before the heating mantle was removed and the solution was allowed to cool down. Finally, $10 \mathrm{ml}$ of toluene was injected into the flask at $100^{\circ} \mathrm{C}$, yielding an orange solution. The produced solution was cleaned by two consecutive steps of centrifuge-assisted precipitation with methanol and redispersion with hexane and small amounts of octylamine or nonanoic 
acid before redispersion with toluene and precipitation with isopropanol at low rpm speed. The final solution was stored in toluene under inert atmosphere.

\subsection{Photodeposition of palladium}

The photodeposition of palladium was according to ref 3.

In a $5 \mathrm{ml}$ glass vial, the previously prepared CdSe@CdS nanorods $\left(2.16 \cdot 10^{-5}\right.$ moles of Cd atoms determined by absorption according to ref 4 ) were diluted with toluene to a volume of $2 \mathrm{ml}$ and $0.5 \mathrm{mg}$ of TOPO were added. The vial was then sealed with a rubber septum and the solution was purged with nitrogen. The vial was stirred with a magnetic stirrer and illuminated with a 300W Xenon lamp (intensity of $81 \mathrm{~mW}$ ) equipped with a cutoff filter preventing radiation below $400 \mathrm{~nm}$ to pass. $0.2 \mathrm{ml}$ of degassed methanol were injected to the solution, acting as hole scavengers.

Palladium stock solution was prepared by dissolving $0.0101 \mathrm{~g}$ of palladium chloride $\left(\mathrm{PdCl}_{2}\right)$ and $0.0444 \mathrm{~g}$ of didodecyldimethylammonium bromide (DDAB) in $5 \mathrm{ml}$ of toluene. The solution was sonicated and stirred for a few hours until a clear dark red solution was obtained. In a separate container, a $0.036 \mathrm{M}$ solution of octadecylamine (ODA) in toluene was prepared by dissolving ODA in toluene with mild heating. The Pd solution and the ODA solution were injected together in small amounts of $0.1 \mathrm{ml}$ consecutively until the solution changed color. Overall the solution was illuminated for 20-25 minutes before the xenon lamp was turned off. During the illumination the solution's color turned from orange to brown. The solution was cleaned by precipitation with methanol and re-dispersion in toluene.

\subsection{Photodeposition of silver}

The silver stock solution was prepared by dissolving $0.0025 \mathrm{~g}$ of $\mathrm{AgNO}_{3}$ and $0.020 \mathrm{~g}$ of $\mathrm{DDA}$ (Didodecylamine) in $2 \mathrm{ml}$ of ethanol. The deposition of Ag was similar to that of Pd with the exception of methanol addition since ethanol which also serves as a hole scavenger was already a part of the silver stock solution. Addition of silver stock solution was done by injection of small volumes $(\sim 0.1 \mathrm{ml})$ of the stock solutions until a change in color was noticed. For the various Ag loadings samples, the number of injections was increased in order to achieve higher loadings of Ag.

\subsection{Mixed depositions}

Depositions of more than one metal were performed in two manners. For a core-shell arrangement of two metals, the deposition of a second metal was performed on already deposited nanorods in order to form a shell around the pre-existing metal. For a mixed alloy arrangement; simultaneous photodeposition was performed by injecting two stock solutions of two metals together.

\subsection{Ligand exchange}

The ligand exchange procedure was done according to ref 5 and performed in the same manner for all the samples. A mixture of 11-mercatoundecanoic acid (MUA), the replacing polar ligand that will allow the particles to disperse in the aqueous medium, and tetramethylammonium hydroxide pentahydrate (TMAH) were dissolved in methanol. Nanoparticles solutions were precipitated with methanol. The precipitate was then re-dispersed in the MUA-TMAH solution. The new solution was precipitated with toluene and eventually dispersed in water. 


\section{Characterization}

\subsection{Transmission electron microscopy (TEM)}

Transmission electron microscopy (TEM) images were acquired with FEI Tecnai T12 microscope, operated with an accelerating voltage of $120 \mathrm{kV}$.

\subsection{High-resolution scanning transmission electron microscopy (STEM)}

High-resolution scanning transmission electron microscopy (STEM) images and EDS maps were recorded in a double aberration-corrected Themis Z microscope (Thermo Fisher Scientific Electron Microscopy Solutions, Hillsboro, USA) equipped with a high-brightness FEG. An accelerating voltage of $80 \mathrm{kV}$ was used to avoid knock-on radiation damage. HAADF images were recorded with a Fischione Model 3000 detector with a semi-convergence angle of $26 \mathrm{mrad}$, a probe current of $40 \mathrm{pA}$, and an inner collection angle of 70.0 mrad. EDS hyperspectral data were obtained with a Super-X G2 four-segment SDD detector with a probe semi-convergence angle of $35.9 \mathrm{mrad}$, a beam current of approximately $100 \mathrm{pA}$, a pixel dwell time of 20 microseconds and a total recording time of typically 10 minutes. Quantitative maps were calculated with the Velox software (Thermo Fisher Scientific Electron Microscopy Solutions, Hillsboro, USA), through background subtraction and spectrum deconvolution.

\section{Photocatalysis measurements}

\subsection{Hydrogen evolution}

Isopropanol (IPA, 2.0ml) served as a hole scavenger and was added to $6.0 \mathrm{ml}$ of aqueous photocatalyst solution with a $\mathrm{pH}$ of 12 in order to form a 25\% IPA solution in water.

The photocatalyst solution was then purged in gas-tight cell with a $2 \mathrm{~cm}$ deep circular cavity. Argon was flowed over the top of the solution by way of an inlet and outlet in the cell. The outlet led to the sample inlet of a gas chromatograph (GC) with a thermal conductivity detector (TCD). In the cell, the solution was purged with argon at a typical flow rate of $9 \mathrm{ml} / \mathrm{min}$ for a few hours until oxygen and nitrogen levels were below the detection limit of the GC. The solution's concentrations were evaluated according to their respective absorbance spectra and kept the same for measurements of the same batch.

Once the solution was fully purged, the cell was illuminated through a quartz window by a $455 \mathrm{~nm}$ wavelength light source (THORLABS - mounted high-power LED) with a FWHM of 20nm. Illumination at this wavelength is absorbed efficiently by the photocatalyst particles and leads to the formation of excitons with sufficient energy for the water reduction. The power measured by the light detector (THORLABS - Digital Handheld Laser Power and Energy Meter Console) was typically $50 \mathrm{~mW}$ which corresponds to a photon flux of $1.1453 \cdot 10^{17}$ photons/sec.

Illumination and measurement were typically done for around 36 hours in order to monitor the trends in the photocatalytic process and follow the dynamic processes which occur during the measurement. the decrease in the water level with time due to evaporation, led to an increase in the distance between the solution and the LED. Therefore, less photons reached the solution with time. In order to overcome this problem, there was a need to open the cell every time the level of hydrogen started to decrease and add solution to maintain a total volume of $8 \mathrm{ml}$. In most cases we measured the first $18 \mathrm{~h}$ then added solution back to original volume, we than measured for additional $6 \mathrm{~h}$ before readjusting the solution level again and measuring for another 
13h. Over this time, hydrogen measurements were taken every 11 minutes using an automated injection system.

The hydrogen gas levels were detected with an online GC (Agilent technologies 7820 A) equipped with a TCD. The peaks' areas were calibrated to amounts of hydrogen gas produced per second by constructing a calibration curve based on electrolysis. Using Pt electrodes which were connected to an external power source, electrolysis of water was performed in constant electric currents. By controlling the current, we were able to calculate the amount of $\mathrm{H}_{2}$ molecules produced per second and fit it to the obtained peak area. The calibration was performed under the same argon flow and the same water level as in the photocatalytic measurements. It was assumed that all current went towards water splitting, and so for each pair of electrons passed, one molecule of hydrogen was created. The GC-TCD signal at various currents was used to build a linear calibration curve of values of $\mathrm{H}_{2}$ molecules produced per sec vs the peaks areas.

\subsection{Quantum efficiency}

The quantum efficiency $(\mathrm{QE})$ is calculated as follows:

$$
\begin{aligned}
& \mathrm{QE} \%=\frac{\text { number of Photons converted to } \mathrm{H}_{2} \text { gas }}{\text { number of photons absorbed }} \cdot 100 \% \\
& \mathrm{QE} \%=\frac{2 \cdot\left(\mathrm{H}_{2} \text { molecules }\right)}{\text { photons flux } \cdot\left(1-\frac{\mathrm{I}}{\mathrm{I}_{0}}\right)} \cdot 100 \% \\
& \mathrm{QE} \%=\frac{2 \times\left(\mathrm{H}_{2} \text { molecules } / \mathrm{sec}\right)}{\frac{\mathrm{P}}{\mathrm{E}_{(\lambda=455 \mathrm{~nm})}} \cdot\left(1-10^{-2 \cdot \mathrm{A}}\right)^{\mathrm{photons} / \mathrm{sec}}} \cdot 100 \%
\end{aligned}
$$

Where $P$ is power of the light source in watts, $E_{(\lambda=455 \mathrm{~nm})}$ - wavelength energy in joule, I is the transferred light intensity, $I_{0}$ is the projected light intensity, $1-\frac{\mathrm{I}}{\mathrm{I}_{0}}=1-10^{-2 \mathrm{~A}}$ is the fraction of the absorbed light according to the Beer-Lambert Law.

The absorption $A$ is measured with a cuvette of $1 \mathrm{~cm}$, but the reactor is $2 \mathrm{~cm}$ in depth and therefore we used 2A for the calculated absorption. For all the measurements the absorbance was kept approximately at $\mathrm{A}=1$ so that $99 \%$ from the photon flux is absorbed by the particles.

\section{Structural and optical features of the various photocatalysts}

For this study, four different batches of CdSe@CdS seeded rods were synthesized from a single batch of CdSe cores, to be used as substrate for the growing of bimetallic tips. The dimensions of the structures, the metal loading used and the max QE\% value, are presented in Tables S1-S4. 
Table S1 - Structural features and maximal QE of all the monometallic Pd photocatalysts (batch I and batch III)

\begin{tabular}{|c|c|c|c|c|c|c|c|}
\hline \multirow{2}{*}{ Batch } & Sample & $\begin{array}{c}\text { Length } \\
\text { (nm) }\end{array}$ & $\begin{array}{c}\text { Width } \\
\text { (nm) }\end{array}$ & $\begin{array}{c}\text { Tip size } \\
\text { (nm) }\end{array}$ & $\begin{array}{c}\text { Metal } \\
\text { loading } \\
\text { (fraction) }\end{array}$ & $\begin{array}{c}\text { Measured } \\
\text { max } \\
\text { QE\% }\end{array}$ & $\begin{array}{c}\text { Max QE, } \\
\text { normalized } \\
\text { to tipped } \\
\text { rods }\end{array}$ \\
\hline \multirow{4}{*}{ I } & NR & $50 \pm 2$ & $5.1 \pm 0.4$ & & & & \\
\cline { 2 - 8 } & $\operatorname{Pd}(1.5 \mathrm{~nm})$ & $49 \pm 3$ & $5.0 \pm 0.6$ & $1.5 \pm 0.4$ & 0.01 & 24 & 29 \\
\cline { 2 - 8 } & $\operatorname{Pd}(3.0 \mathrm{~nm})$ & $47 \pm 4$ & $4.9 \pm 0.5$ & $3.0 \pm 0.5$ & 0.04 & 61 & 73 \\
\cline { 2 - 8 } & $\operatorname{Pd}(4.5 \mathrm{~nm})$ & $45 \pm 4$ & $4.8 \pm 0.4$ & $4.5 \pm 0.3$ & 0.10 & 22 & 24 \\
\hline \multirow{3}{*}{$\mathrm{III}$} & $\mathrm{NR}$ & $59 \pm 2$ & $5.1 \pm 0.3$ & & & & \\
\cline { 2 - 8 } & $\mathrm{Pd}(2.2 \mathrm{~nm})$ & $52 \pm 3$ & $5.0 \pm 0.5$ & $2.2 \pm 0.2$ & 0.01 & 75 & 91 \\
\cline { 2 - 8 } & $\mathrm{Pd}(4.3 \mathrm{~nm})$ & $52 \pm 4$ & $4.8 \pm 0.3$ & $4.3 \pm 0.6$ & 0.07 & 23 & 25 \\
\hline
\end{tabular}
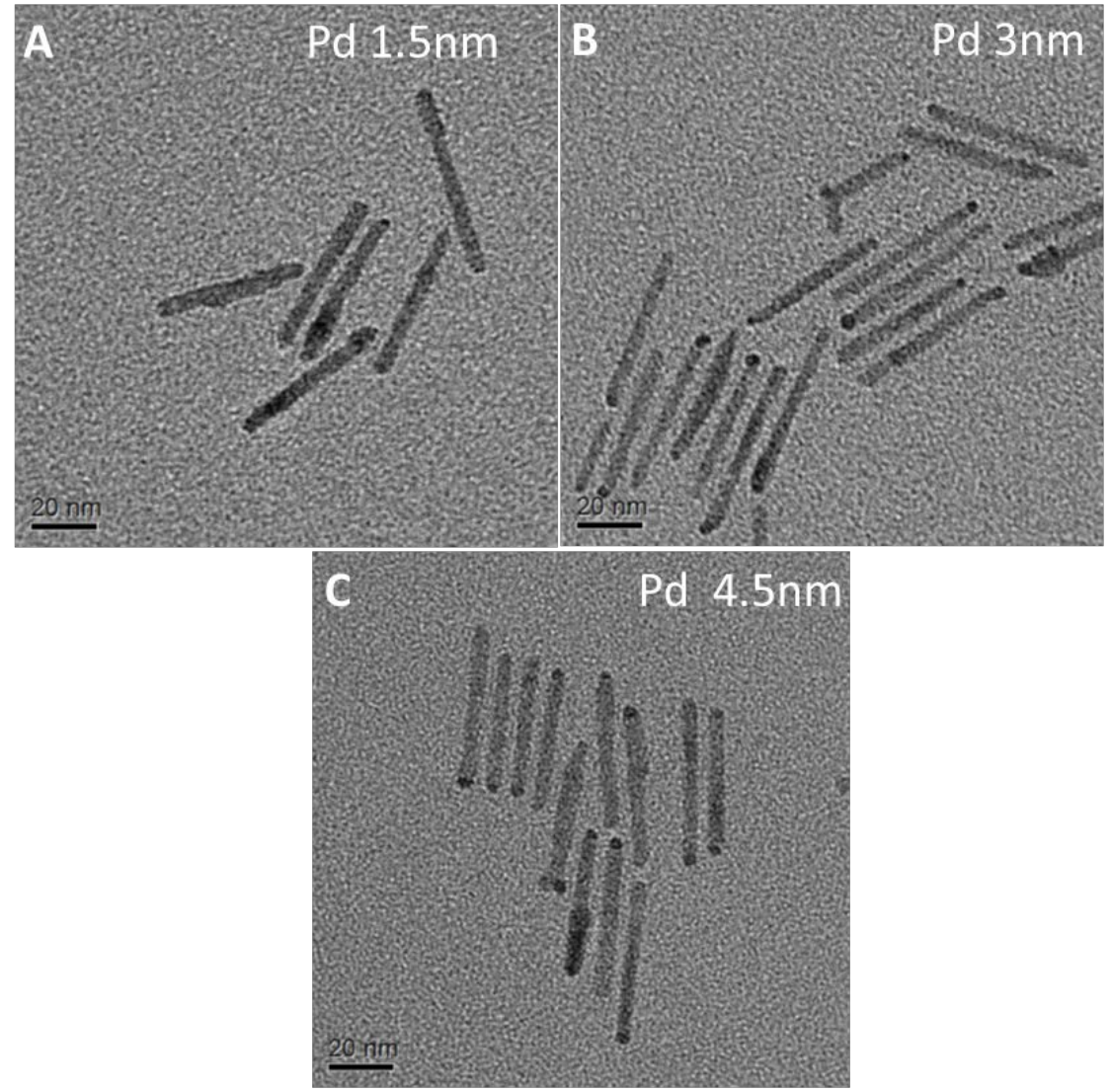

Figure S1. TEM images of Pd tips in different sizes, deposited on the seeded rods of batch I. 


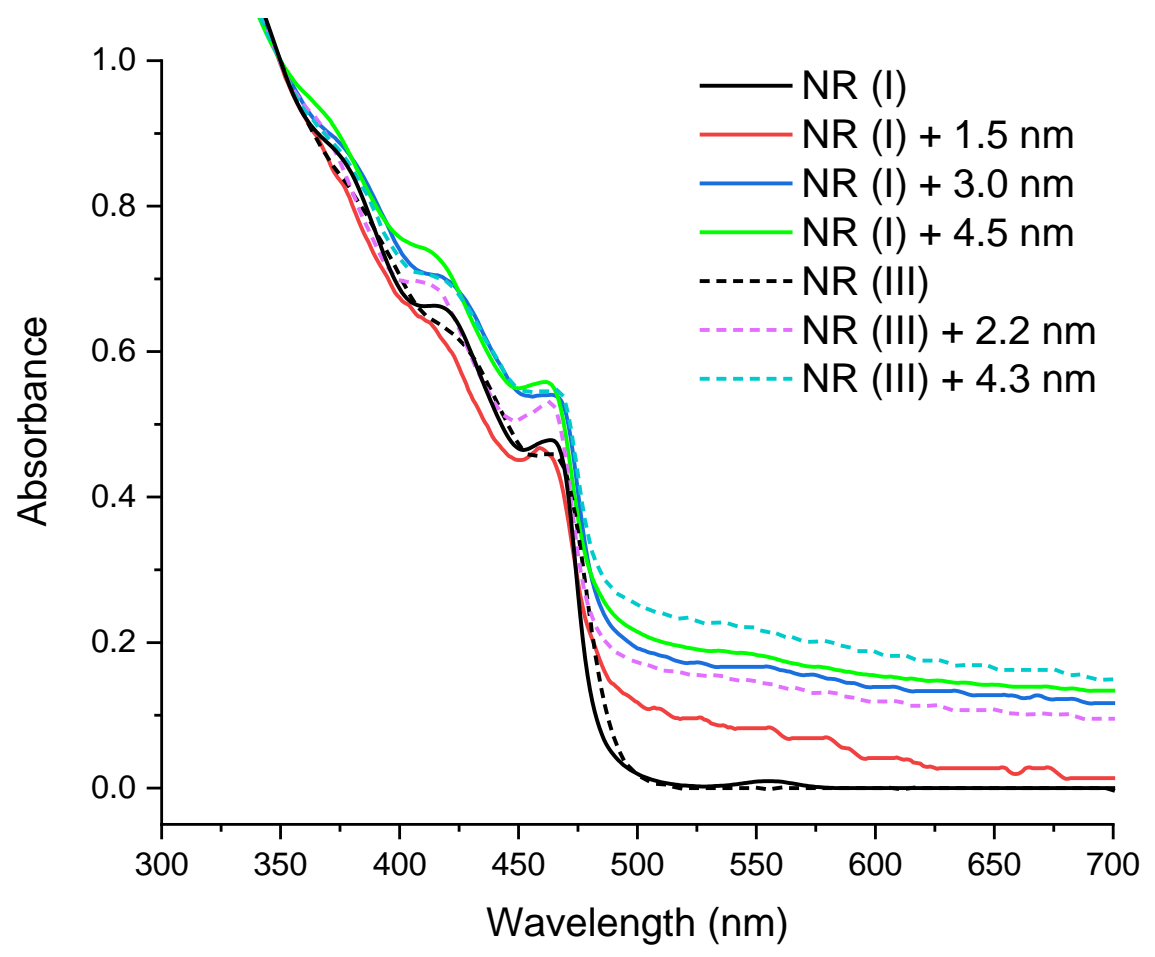

Figure S2. UV-Vis absorption spectra for the samples containing mono-metallic Pd. All the samples were normalized to the absorption at $350 \mathrm{~nm}$. Solid lines correspond to samples based on NR (I) and dashed lines correspond to samples based on NR (III). Note: although the typical absorbance of the CdSe core (2.2 $\mathrm{nm}$ in diameter) is hardly visible in these graphs, its existence within the nanorods was confirmed by PL measurements for all the NR.

Table S2 - Structural features for the monometallic Ag photocatalysts

\begin{tabular}{|c|c|c|c|c|c|}
\hline \multirow{3}{*}{ Batch } & Sample & $\begin{array}{c}\text { Length } \\
\text { (nm) }\end{array}$ & $\begin{array}{c}\text { Width } \\
\text { (nm) }\end{array}$ & $\begin{array}{c}\text { Tip size } \\
\text { (nm) }\end{array}$ & $\begin{array}{c}\text { Metal } \\
\text { Loading } \\
\text { (fraction) }\end{array}$ \\
\hline \multirow{7}{*}{ II } & NR & $92 \pm 5$ & $5.3 \pm 0.5$ & & \\
\cline { 2 - 6 } & $\mathrm{Ag}(1 \% \mathrm{Ag})$ & $90 \pm 4$ & $5.1 \pm 0.5$ & $2.2 \pm 0.5$ & 0.01 \\
\cline { 2 - 6 } & $\mathrm{Ag}(5 \% \mathrm{Ag})$ & $84 \pm 6$ & $5.0 \pm 0.6$ & $3.8 \pm 0.3$ & 0.05 \\
\cline { 2 - 6 } & $\mathrm{Ag}(10 \% \mathrm{Ag})$ & $87 \pm 7$ & $4.9 \pm 0.4$ & $4.6 \pm 0.6$ & 0.10 \\
\cline { 2 - 6 } & $\mathrm{Ag}(40 \% \mathrm{Ag})$ & $82 \pm 4$ & $4.9 \pm 0.5$ & $5.1 \pm 0.3$ & 0.40 \\
\hline
\end{tabular}



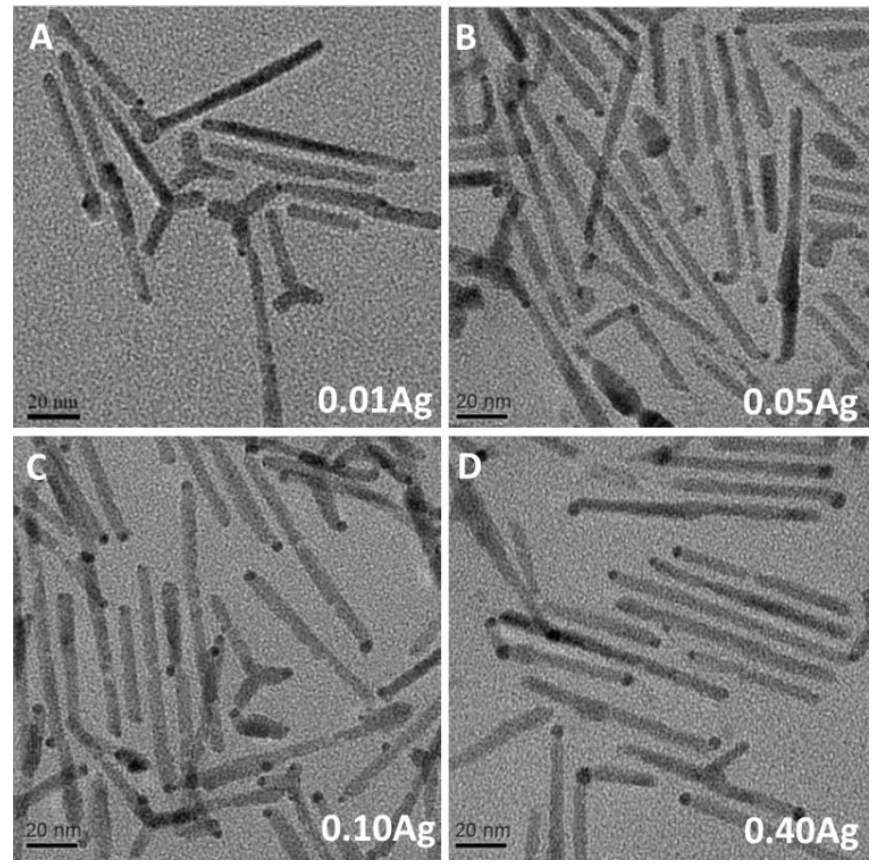

Figure S3. TEM images of Ag tips with different loadings, deposited on the seeded rods of batch II. The loading fraction is marked on each image.

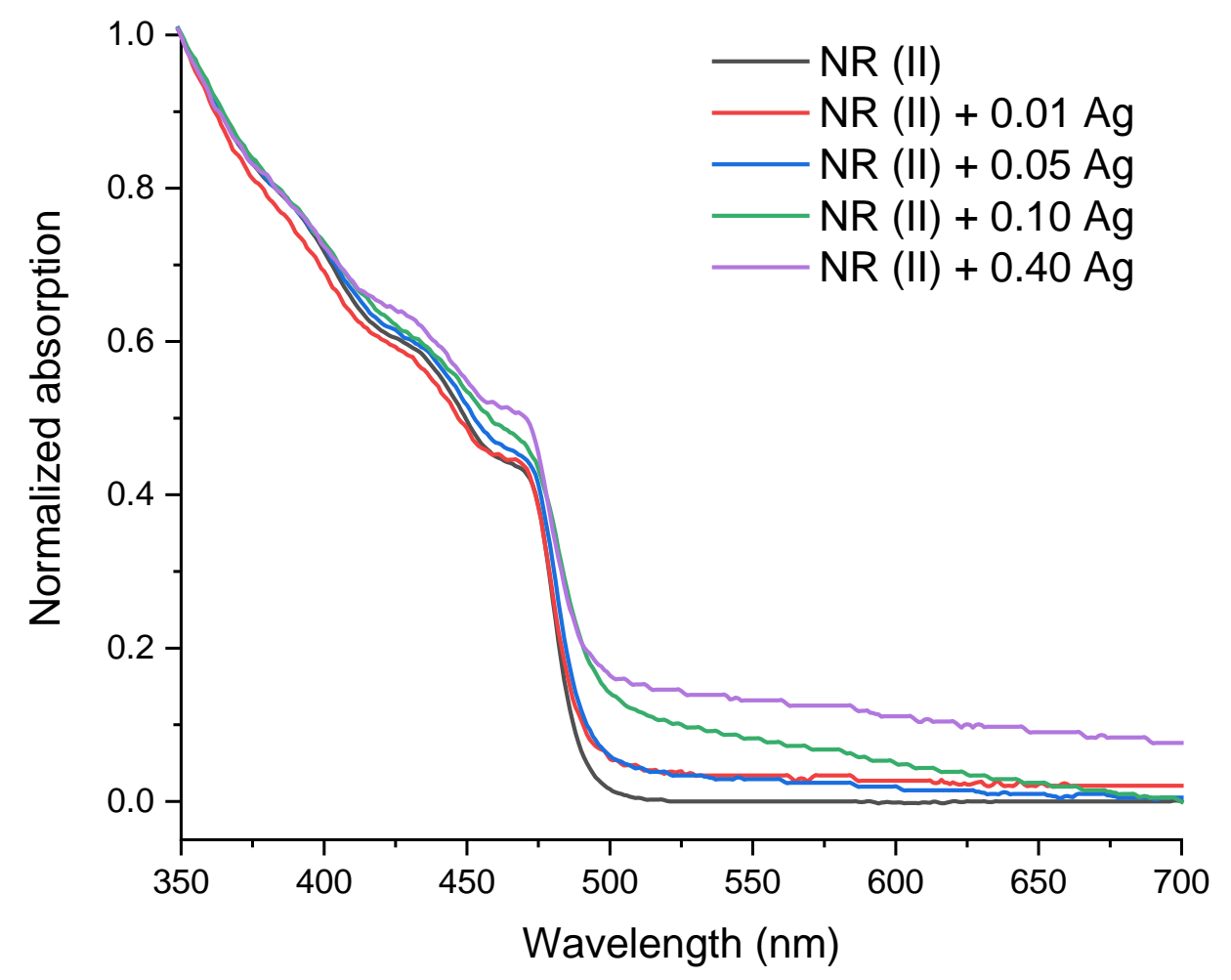

Figure S4. UV-Vis absorption spectra of the Ag tipped seeded rods of batch II. All the samples were normalized to the absorption at $350 \mathrm{~nm}$. Note: although the typical absorbance of the CdSe core $(2.2 \mathrm{~nm}$ in diameter) is hardly visible in these graphs, its existence within the nanorods was confirmed by PL measurements for all the NR. 
Table S3. Structural features and maximal QE for the bimetallic photocatalysts (batch III)

\begin{tabular}{|c|c|c|c|c|c|c|c|}
\hline Batch & Sample & $\begin{array}{c}\text { Length } \\
\text { (nm) }\end{array}$ & $\begin{array}{l}\text { Width } \\
\text { (nm) }\end{array}$ & $\begin{array}{l}\text { Tip size } \\
\text { (nm) }\end{array}$ & $\begin{array}{c}\text { Metal } \\
\text { loading } \\
\text { (fraction) }\end{array}$ & $\begin{array}{c}\text { Measured } \\
\text { max } \\
\text { QE\% }\end{array}$ & $\begin{array}{c}\text { Max QE, } \\
\text { normalized to } \\
\text { tipped rods }\end{array}$ \\
\hline \multirow{7}{*}{ III } & NR & $59 \pm 2$ & $5.1 \pm 0.3$ & & & & \\
\hline & $\mathrm{Ag}$ & $58 \pm 4$ & $4.9 \pm 0.4$ & $3.7 \pm 0.3$ & 0.05 & 0.8 & 1.1 \\
\hline & $\mathrm{Pd}(2.2 \mathrm{~nm})$ & $52 \pm 3$ & $5.0 \pm 0.5$ & $2.2 \pm 0.2$ & 0.01 & 75 & 91 \\
\hline & $\mathrm{Pd}(4.3 \mathrm{~nm})$ & $52 \pm 4$ & $4.8 \pm 0.3$ & $4.3 \pm 0.6$ & 0.07 & 23 & 25 \\
\hline & $\begin{array}{l}\text { Ag-Pd } \\
\text { (alloy) }\end{array}$ & $53 \pm 2$ & $4.7 \pm 0.8$ & $3.0 \pm 0.7$ & 0.04 & 33 & 41 \\
\hline & $\begin{array}{l}\text { Ag@Pd } \\
\text { core-shell }\end{array}$ & $58 \pm 3$ & $4.7 \pm 0.6$ & $3.1 \pm 0.6$ & 0.04 & 33 & 41 \\
\hline & $\begin{array}{l}\text { Pd@Ag } \\
\text { core-shell }\end{array}$ & $50 \pm 3$ & $4.8 \pm 0.4$ & $3.9 \pm 0.5$ & 0.05 & 12 & 14 \\
\hline
\end{tabular}

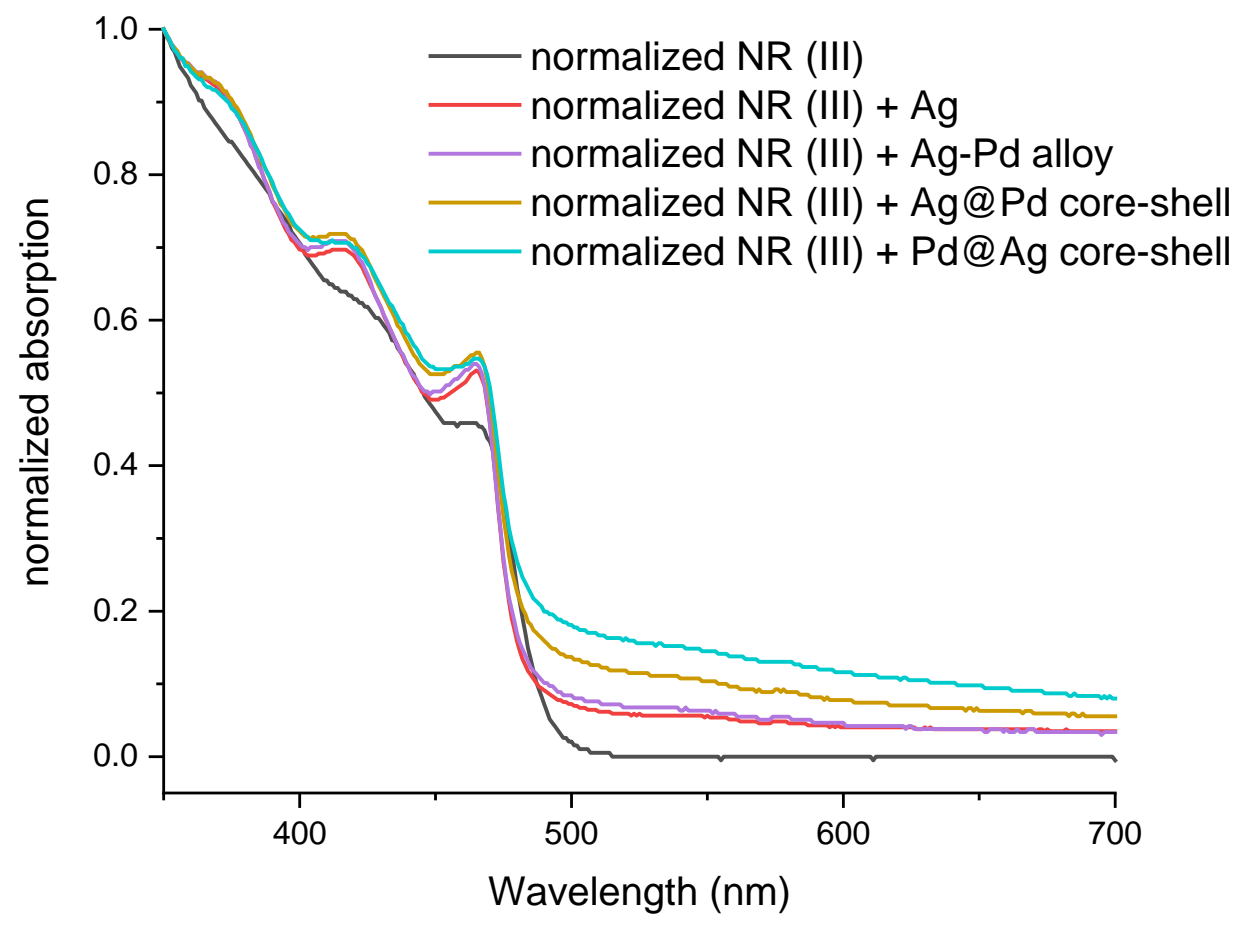

Figure S5. UV-Vis absorption spectra of the bimetallic tips of batch III. Note: although the typical absorbance of the CdSe core (2.2 nm in diameter) is hardly visible in these graphs, its existence within the nanorods was confirmed by PL measurements for all the NR. 
Table S4. Structural features and maximal QE for the bimetallic photocatalysts (batch IV)

\begin{tabular}{|c|l|c|c|c|c|c|c|}
\hline Batch & Sample & $\begin{array}{c}\text { Length } \\
\text { (nm) }\end{array}$ & $\begin{array}{c}\text { Width } \\
\text { (nm) }\end{array}$ & $\begin{array}{c}\text { Tip size } \\
\text { (nm) }\end{array}$ & $\begin{array}{c}\text { Metal } \\
\text { Loading } \\
\text { (fraction) }\end{array}$ & $\begin{array}{c}\text { Measured } \\
\text { max } \\
\text { QE\% }\end{array}$ & $\begin{array}{c}\text { Max QE, } \\
\text { normalized to } \\
\text { tipped rods }\end{array}$ \\
\hline \multirow{2}{*}{ IV } & NR & $53 \pm 3$ & $5.2 \pm 0.4$ & & & & \\
\cline { 2 - 8 } & $\begin{array}{l}\text { Ag-Pd } \\
\text { (alloy) }\end{array}$ & $46 \pm 3$ & $4.7 \pm 0.5$ & $5.0 \pm 0.3$ & 0.50 & 1 & 1 \\
\cline { 2 - 8 } & $\begin{array}{l}\text { Ag@Pd } \\
\text { core-shell }\end{array}$ & $50 \pm 4$ & $5.0 \pm 0.3$ & $4.4 \pm 0.3$ & 0.50 & 0 & 0 \\
\cline { 2 - 8 } & $\begin{array}{l}\text { Pd@Ag } \\
\text { core-shell }\end{array}$ & $49 \pm 4$ & $5.2 \pm 0.3$ & $5.8 \pm 0.5$ & 0.60 & 10 & 10 \\
\hline
\end{tabular}

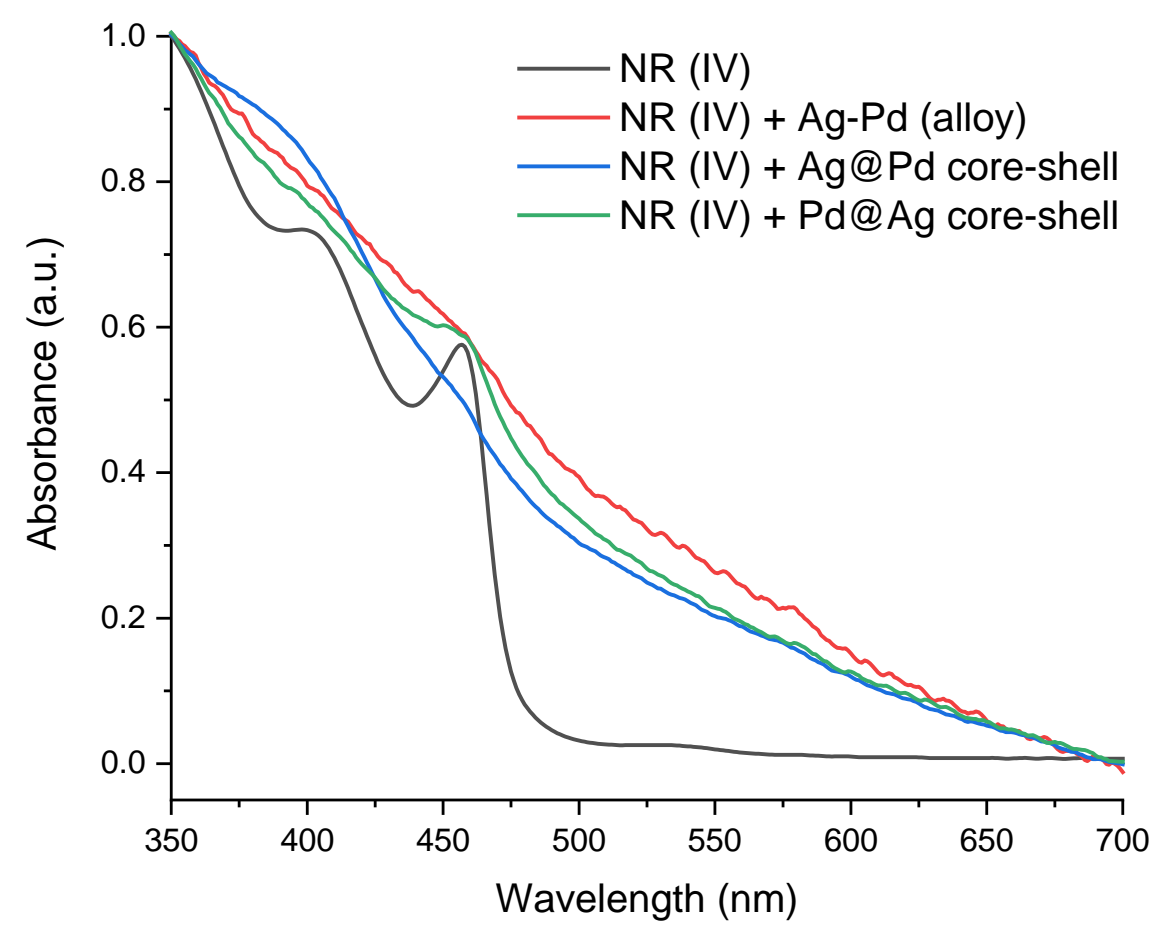

Figure S6. UV-Vis absorption spectra of the bimetallic tips of batch IV. Note: although the typical absorbance of the CdSe core (2.2 nm in diameter) is hardly visible in these graphs, its existence within the nanorods was confirmed by PL measurements for all the NR.

The photocatalysts were monitored by extracting aliquots in certain intervals during the photocatalytic measurements and by examining them using TEM. The images of the structures in various stages of the photocatalysis are presented in Figure S7. Due to their strong contrast in the TEM images, the metal tips appear as clearly visible black dots on the edge of the rods, most of which show a single metal tip.

An illustration of the measured photocatalysts is presented in Figure S7 along with the TEM images before and after 24 and 36 hours of photocatalysis. Even though some etching was noticed with time, the overall 
structure of the rods remained intact. The TEM images show that there is no significant change in the overall structure of the photocatalysts and none of the samples were destroyed as a result of the photocatalysis. That means that variations in activity which occur with time are minor.

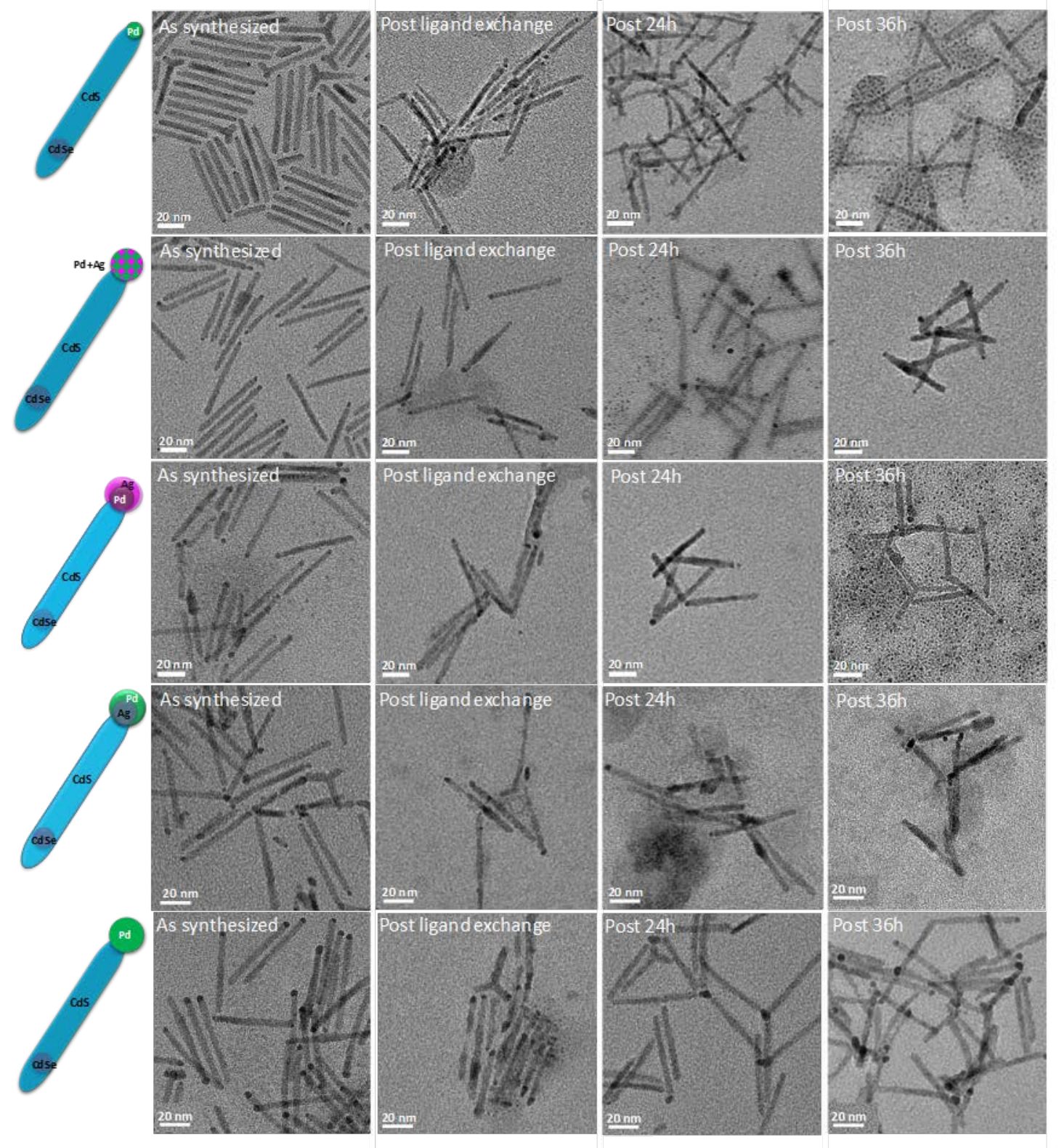

Figure S7. Illustrations of the various photocatalysts and their corresponding TEM images in different stages (from left to right); post ligand exchange (pre illumination), post 24h of illumination and post $36 \mathrm{~h}$ of illumination. 


\section{Low-voltage TEM to reduce the radiation damage of the CdSe@CdS nanorod structure}

High-resolution TEM and STEM images and STEM-EDS data were taken at an acceleration voltage of 80 $\mathrm{kV}$ in order to reduce the effect of radiation damage. The primary damage in semiconductors and metals is through energy deposited in a recoil impact of a high-energy electron with a lattice atom and the subsequent displacement of the atom (knock-on damage). The ballistic displacement cross-sections are described well by the McKinley-Feshbach formalism, a series expansion of the Mott scattering formula for the collision between a relativistic electron and an atom nucleus. ${ }^{6}$ The mean displacement energy for $\mathrm{S}$ in CdS, determined from experiment, is about $9.6 \mathrm{eV} .{ }^{7}$ We could not find in the literature the information for $\mathrm{Ag}_{2} \mathrm{~S}$, but the values for other semiconductors varied from 6.15-9.2 eV. ${ }^{8}$ Figure S8 shows the effectiveness of reducing the electron acceleration voltage for elimination of knock-on radiation damage. The calculation in Figure S8 shows the knock-on damage cross-sections for sulfur, the lightest element in the hybrid nano rod structure, calculated with the McKinley-Feshbach equation for three different displacement energies: 6 $\mathrm{eV}, 7 \mathrm{eV}$, and $8 \mathrm{eV}$ - all values that are within the range described in ref. 8. Knock-on sputter damage is expected for an acceleration voltage much larger than the $80 \mathrm{kV}$ used in our experiment. When working with $200 \mathrm{kV}$, a significant damage is both predicted by the calculation (even though the discussion here is idealized) and observed experimentally. Radiolysis, thermal heating and radiation induced desorption from surfaces are of minor importance and therefore not included here; chemical etching was minimized by avoiding water background pressure in the high vacuum of the microscope chamber.

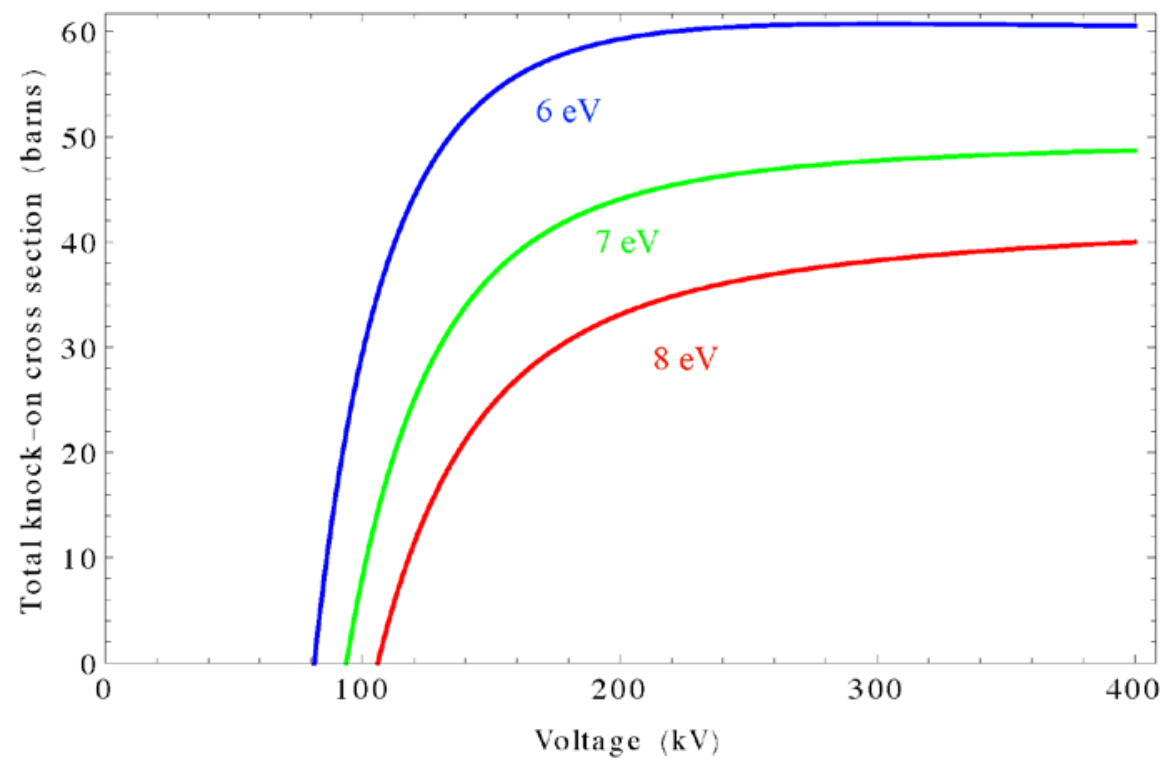

Figure S8. Knock-on damage cross-sections for sulfur in the TEM, calculated with the McKinleyFeshbach equation for three different displacement energies: $6 \mathrm{eV}, 7 \mathrm{eV}$, and $8 \mathrm{eV}$. 


\section{Composition of seeded CdSe@CdS -Ag nanorods with different Ag loadings}
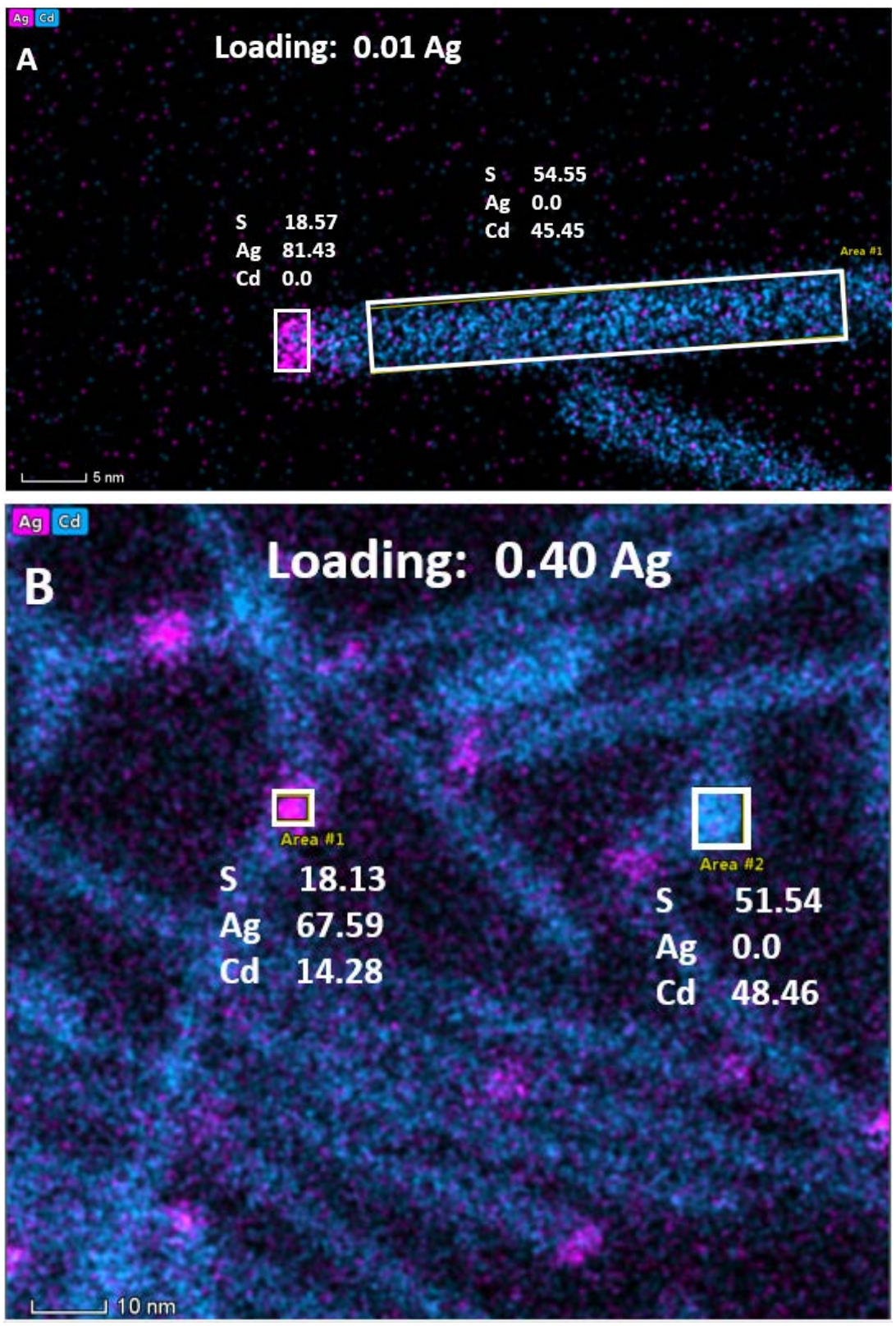

Figure S9: STEM-EDS elemental maps of SdSe@CdS-Ag hybrid nanorods produced with two different loadings of Ag. (a) Low loading Ag: $\mathrm{Cd}=0.01$, (b) high loading Ag: $\mathrm{Cd}=0.40$. The maps show the distribution of $\mathrm{Cd}$ and Ag; the elemental composition in atomic percentage is indicated for selected regions. Within the precision of the measurement stoichiometric CdS is found along the nanorods. Ag is concentrated in the tips, where residual signal of $\mathrm{Cd}$ and S may be present because of overlap of the tip with a part of the CdS nanorod in transmission (in b) or as background that is observed on the supporting grid close by (in a). 


\section{Note: QE corrections}

\section{Correction for the fraction of bare rods}

Our prior studies show that bare seeded rods have negligible catalytic activity. Therefore, the QE should be normalized to the fraction of active structures within the sample. Table S5 presents the measured maximum $\mathrm{QE}$, the fraction of tipped rods within the sample (based on statistics from TEM images) and the corrected max QE.

Table S5. Correction of the QE for the fraction of bare rods within the sample. The correction is made by dividing column B with column A and presenting the result in percent.

A

B

$\mathrm{C}=\mathrm{B} / \mathrm{A} * 100$

\begin{tabular}{|c|c|c|c|}
\hline & \% tipped rods & Measured max QE (\%) & $\begin{array}{c}\text { Max QE, normalized to } \\
\text { tipped rods (\%) }\end{array}$ \\
\hline NR III & & & \\
\hline Ag & 76 & 75 & 1.1 \\
\hline Pd (2.2nm) & 82 & 23 & 91 \\
\hline Pd (4.3nm) & 92 & 33 & 25 \\
\hline Ag-Pd (alloy) & 81 & 33 & 41 \\
\hline Ag@Pd core-shell & 80 & 12 & 41 \\
\hline$P d @ A g$ core-shell & 86 & & 14 \\
\hline NR I & & 24 & 29 \\
\hline Pd (1.5 nm) & 82 & 61 & 73 \\
\hline$P d(3.0 \mathrm{~nm})$ & 83 & 22 & 24 \\
\hline Pd (4.5 nm) & 93 & & 1 \\
\hline NR IV & & 1 & 0 \\
\hline Ag-Pd (alloy) & 100 & 0 & 10 \\
\hline Ag@Pd core-shell & 100 & 10 & \\
\hline$P d @ A g$ core-shell & 100 & & \\
\hline
\end{tabular}

\section{Correction for the fraction semiconductor from the overall structure}

Photons that are absorbed directly by the intraband transitions of the metal tip are assumed not to contribute to the generation of hydrogen due to their rapid relaxation. ${ }^{9-11}$ Therefore scaling the hydrogen production only to the semiconductor component of the tipped seeded rods was performed by a few methods. ${ }^{9-11}$ The total absorption of such seeded rods - metal hybrid nanoparticles was considered in first approximation as the superposition of the contributions of the exciton and the plasmon. ${ }^{9-11}$ As the contribution of the metal to the overall absorbance increases with tip size, it becomes more important to correct the photocatalytic hydrogen generation when the fraction of the metal within the sample becomes significant.

I) Assuming that the absorption is proportional to the molar fraction (similar to ref. 10, where the QE was corrected by the fraction of $\mathrm{Cd}$ atoms from the metal content of the sample) and that the molar fraction can be calculated by the geometric dimensions, we estimated the fraction of the semiconductor in the hybrid 
structures as the fraction of Cd to co-catalyst metal atoms (Table S6). The unit cell of CdS occupies 0.195 $\mathrm{nm}^{3}$ (average of Wurtzite and Zinc Blende ${ }^{12}$ ), and each until cell contains $2 \mathrm{Cd}$ atoms. For FCC Pd, the cell volume is $\mathrm{V}=a^{3}=(0.386 \mathrm{~nm})^{3}=0.058 \mathrm{~nm}^{3}$ and calculated for Ag in the same way $\mathrm{V}=a^{3}=(0.408 \mathrm{~nm})^{3}=0.068$ $\mathrm{nm}^{3} .^{13}$ An average was taken for the bimetallic tips: $0.063 \mathrm{~nm}^{3}$. Each unit cell contains 4 atoms. The number of $\mathrm{Cd}$, Ag or Pd atoms was calculated by dividing the relevant volume by the suitable unit cell volume and multiplying by the number of atoms in a unit cell. Column $C$ was calculated as $C=100 * A /(A+B)$. Column $\mathrm{D}$ was copied as is from Table S5. Column E was calculated as E=100*D/C.

II) Assuming that the absorption is proportional to the volume of the materials, a correction of the \%QE values is possible based on the geometrical dimensions. Column F in Table S6 is the ratio of the metal volume to the overall volume of the structure. Column $\mathrm{G}$ is the corrected \%QE based on the volume ratio. In this size range it may be even more accurate to correct relative to the surface area of the nanoparticles, and the results are somewhat shifted but again, the trend fully consistent with the volume correction.

After applying the correction to the QE, all the QE values were increased. A comparative graph is presented in Figure S10, showing that although the corrections are more significant in the structures with larger tips, the overall trend is maintained, probably because in our study the metal to semiconductor ratio is not as high as in other studies.

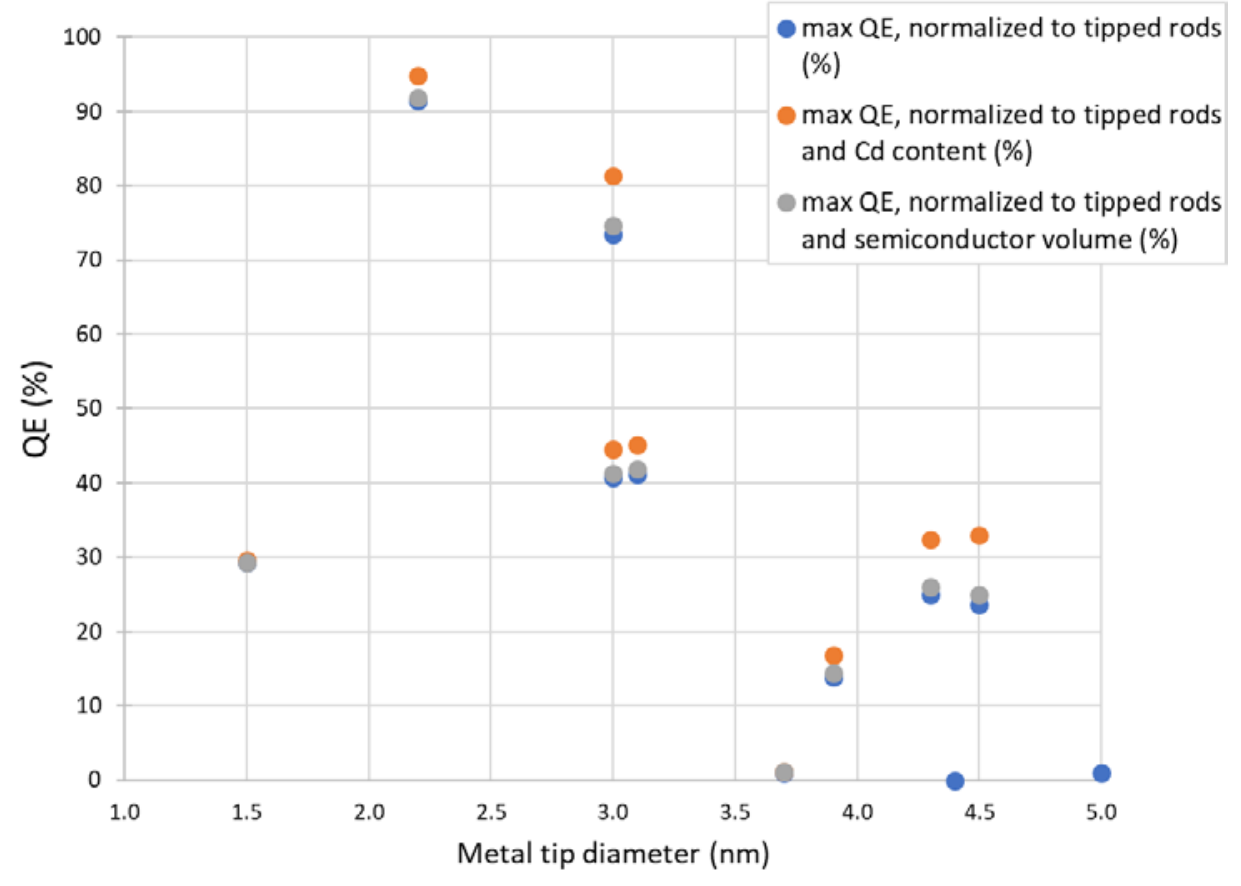

Figure S10. The \%QE vs. metal tip size, corrected by different methods.

Others used different correction factors, but a direct comparison between corrections applied to seeded rods with similar metal tip sizes should be done with caution, since corrections should be scaled to the co-catalyst metal to Cd ratio, such that longer rods will be less affected by the correction. Moreover, the correction according to molar ratio alone neglects the different optical properties of the metal co-catalysts, and therefore it should be referred to as a first approximation. In addition, these calculations are based on maintaining the same morphology, while in the higher loadings the single -tipped rod morphology does not exist anymore: we detect multiple decorations of small metal particles (that can be very active co-catalysts) 
and cation exchange processes, potentially producing other semiconductors. Considering all the abovementioned points, a direct comparison of the correction for the higher loading with the smaller tips is probably invalid.

Another approach for the QE correction was based on UV-Vis absorbance, when Ni was used as the cocatalyst. ${ }^{11}$ Similarly to Pd it has an almost featureless decaying absorbance spectrum in the range 300-700 $\mathrm{nm} .{ }^{14-16}$ By the subtraction of the bare rod absorbance from that of the metal-tipped rod, the residual spectrum (ascribed to the metal absorption) could be fit and extrapolated. The fit should be performed at the range 500-700 nm, where the interaction between the metal tip and the CdS does not have a significant effect on the spectrum. ${ }^{11}$ Using the fact that the metal absorbance is quite smooth, a polynomial fit can be extrapolated to $350 \mathrm{~nm}$, and the difference between the metal absorbance and the tipped rod absorbance at $350 \mathrm{~nm}$ is the contribution of the semiconductor. Thereafter the QE is scaled accordingly. While this is true for Ni and Pd, nanoparticles of metals such as Ag (used in our work) and Au (used in ref. 10), under $20 \mathrm{~nm}$, show strongly size-dependent plasmonic features in their absorbance spectrum. ${ }^{17}$ Such a fit as described for the Ni will not be reasonable. Moreover, a hybrid of Ag and Pd can exhibit a dampened plasmon or a featureless spectrum, depending on the morphology (core-shell, thickness of the shell, alloy), ${ }^{18-19}$ making the analysis of the metal fraction absorption quite complex. 
Table S6. Correction of the QE for the fraction of the semiconductor within the photocatalysts.

\begin{tabular}{|c|c|c|c|c|c|c|c|c|c|c|c|c|}
\hline & $\begin{array}{l}\text { Rod } \\
\text { length } \\
(\mathrm{nm})\end{array}$ & $\begin{array}{c}\text { Rod } \\
\text { diameter } \\
(\mathrm{nm})\end{array}$ & $\begin{array}{c}\text { Rod } \\
\text { volume } \\
\left(\mathrm{nm}^{3}\right)\end{array}$ & $\begin{array}{l}\text { Cd atoms } \\
\text { in rod }\end{array}$ & $\begin{array}{c}\text { Tip } \\
\text { diameter } \\
(\mathrm{nm})\end{array}$ & $\begin{array}{c}\text { Tip } \\
\text { volume } \\
\left(\mathrm{nm}^{3}\right)\end{array}$ & $\begin{array}{l}\text { co- } \\
\text { catalyst } \\
\text { atoms in } \\
\text { tip }\end{array}$ & $\begin{array}{l}\text { Cd (\%) } \\
\text { from } \\
\text { metal } \\
\text { content }\end{array}$ & $\begin{array}{c}\text { Max QE, } \\
\text { normalized } \\
\text { to tipped } \\
\text { rods (\%) }\end{array}$ & $\begin{array}{l}\text { Max QE, } \\
\text { normalized } \\
\text { to tipped } \\
\text { rods and } \\
\text { Cd content } \\
(\%)\end{array}$ & $\begin{array}{c}\text { Ratio } \\
\text { semicondu- } \\
\text { ctor } \\
\text { volume to } \\
\text { overall } \\
\text { volume }\end{array}$ & $\begin{array}{c}\text { Max QE, } \\
\text { normalized } \\
\text { to tipped } \\
\text { rods and } \\
\text { semicondu- } \\
\text { ctor } \\
\text { volume (\%) }\end{array}$ \\
\hline NR III & 59 & 5.1 & & & & & & & & & & \\
\hline $\mathrm{Ag}$ & 58 & 4.9 & 1094 & 11218 & 3.7 & 26.5 & 1560 & 87.8 & 1.1 & 1.2 & 97.6 & 1.1 \\
\hline $\mathrm{Pd}(2.2 \mathrm{~nm})$ & 52 & 5 & 1021 & 10472 & 2.2 & 5.6 & 385 & 96.5 & 91 & 95 & 99.5 & 92 \\
\hline $\mathrm{Pd}(4.3 \mathrm{~nm})$ & 52 & 4.8 & 941 & 9651 & 4.3 & 41.6 & 2871 & 77.1 & 25 & 32 & 95.8 & 26 \\
\hline Ag-Pd (alloy) & 53 & 4.7 & 920 & 9431 & 3.0 & 14.1 & 898 & 91.3 & 41 & 45 & 98.5 & 41 \\
\hline $\begin{array}{c}\mathrm{Ag} @ \mathrm{Pd} \\
\text { core-shell }\end{array}$ & 58 & 4.7 & 1006 & 10321 & 3.1 & 15.6 & 990 & 91.2 & 41 & 45 & 98.5 & 42 \\
\hline $\begin{array}{c}\text { Pd@Ag } \\
\text { core-shell }\end{array}$ & 50 & 4.8 & 905 & 9280 & 3.9 & 31.1 & 1972 & 82.5 & 14 & 17 & 96.7 & 14 \\
\hline NR I & 50 & 5.1 & & & & & & & & & & \\
\hline $\mathrm{Pd}(1.5 \mathrm{~nm})$ & 49 & 5 & 962 & 9868 & 1.5 & 1.8 & 122 & 98.8 & 29 & 30 & 99.8 & 29 \\
\hline $\mathrm{Pd}(3.0 \mathrm{~nm})$ & 47 & 4.9 & 886 & 9090 & 3.0 & 14.1 & 975 & 90.3 & 73 & 81 & 98.4 & 75 \\
\hline $\mathrm{Pd}(4.5 \mathrm{~nm})$ & 45 & 4.8 & 814 & 8352 & 4.5 & 47.7 & 3291 & 71.7 & 24 & 33 & 94.5 & 25 \\
\hline NR IV & 53 & 5.2 & & & & & & & & & & \\
\hline Ag-Pd (alloy) & 46 & 4.7 & 798 & 8185 & 5.0 & 65.4 & 4156 & 66.3 & 1.0 & 1.5 & 92.4 & 1.1 \\
\hline $\begin{array}{c}\text { Ag@Pd } \\
\text { core-shell }\end{array}$ & 50 & 5 & 982 & 10069 & 4.4 & 44.6 & 2832 & 78.0 & 0 & 0 & 95.7 & 0 \\
\hline $\begin{array}{l}\text { Pd@Ag } \\
\text { core-shell }\end{array}$ & 49 & 5.2 & 1041 & 10673 & 5.8 & 102.2 & 6486 & 62.2 & 10 & 16 & 91.1 & 11 \\
\hline
\end{tabular}




\section{References}

1. $\quad$ Carbone, L.; Nobile, C.; De Giorgi, M.; Sala, F. D.; Morello, G.; Pompa, P.; Hytch, M.; Snoeck, E.; Fiore, A.; Franchini, I. R. et al. Synthesis and micrometer-scale assembly of colloidal CdSe/CdS nanorods prepared by a seeded growth approach. Nano Lett. 2007, 7, 2942-2950.

2. Chakrabortty, S.; Yang, J. A.; Tan, Y. M.; Mishra, N.; Chan, Y. Asymmetric dumbbells from selective deposition of metals on seeded semiconductor nanorods. Angew. Chem. Int. Edit. 2010, 49, 2888-2892.

3. Li, X., et al., Light-Induced Selective Deposition of Metals on Gold-Tipped CdSe-Seeded CdS Nanorods. J. Am. Chem. Soc. 2010, 133(4), 672-675.

4. Jain, P.K., et al. Nanoheterostructure Cation Exchange: Anionic Framework Conservation. J. Am. Chem. Soc. 2010, 132(29), 9997-9999

5. Amirav, L.; Alivisatos, A. P. Photocatalytic Hydrogen Production with Tunable Nanorod Heterostructures. J. Phys. Chem. Lett. 2010, 1, 1051-1054.

6. McKinley, W.A. Jr.; Feshbach, H. The Coulomb Scattering of Relativistic Electrons by Nuclei, Phys. Rev. 1948, 74, 1759-1763.

7. Bryant, F.Y. Cox, A.F.J. Experimental and Calculated Atomic Displacement Threshold Energies for Binary Semiconductors, Proc. Roy. Soc. A 1969, 310, 319-339.

8. Bryant, F. J.; Cox, A. F. J. Atomic Displacement Energies for Binary Semiconductors J. Phys. C: Solid State Phys. 1968, 1, 1734.

9. Ben-Shahar, Y.; Banin, U., Hybrid Semiconductor-Metal Nanorods as Photocatalysts. Top. Curr. Chem. 2016, 374 (4), 54.

10. Ben-Shahar, Y.; Scotognella, F.; Kriegel, I.; Moretti, L.; Cerullo, G.; Rabani, E.; Banin, U., Optimal metal domain size for photocatalysis with hybrid semiconductor-metal nanorods. Nat. Commun. 2016, 7, 10413.

11. Nakibli, Y.; Mazal, Y.; Dubi, Y.; Wächtler, M.; Amirav, L., Size Matters: Cocatalyst Size Effect on Charge Transfer and Photocatalytic Activity. Nano Lett. 2018, 18 (1), 357-364.

12. Zelaya-angel, O.; Yee-madeira, H.; Lozada-morales, R., Theoretical basis for zincblende to wurtzite CdS-phase transition. Phase Transitions 1999, 70 (1), 11-17.

13. Davey, W. P., Precision Measurements of the Lattice Constants of Twelve Common Metals. Phys. Rev. 1925, 25 (6), 753-761.

14. Li, D.; Komarneni, S., Microwave-Assisted Polyol Process for Synthesis of Ni Nanoparticles. $J$. Am. Ceram. Soc. 2006, 89 (5), 1510-1517.

15. Zhang, J.; Lan, C. Q., Nickel and cobalt nanoparticles produced by laser ablation of solids in organic solution. Mater. Lett. 2008, 62 (10), 1521-1524.

16. Kora, A. J.; Rastogi, L., Green synthesis of palladium nanoparticles using gum ghatti (Anogeissus latifolia) and its application as an antioxidant and catalyst. Arab. J. Chem. 2018, 11 (7), 1097-1106. 
17. Peng, S.; McMahon, J. M.; Schatz, G. C.; Gray, S. K.; Sun, Y., Reversing the size-dependence of surface plasmon resonances. Proc. Natl. Acad. Sci. U.S.A. 2010, 107 (33), 14530-14534.

18. Salem, M. A.; Bakr, E. A.; El-Attar, H. G., Pt@Ag and Pd@Ag core/shell nanoparticles for catalytic degradation of Congo red in aqueous solution. Spectrochim. Acta A 2018, 188, 155-163.

19. Lim, B.; Kobayashi, H.; Yu, T.; Wang, J.; Kim, M. J.; Li, Z.-Y.; Rycenga, M.; Xia, Y., Synthesis of Pd-Au Bimetallic Nanocrystals via Controlled Overgrowth. J. Am. Chem. Soc. 2010, 132 (8), 2506-2507. 